\title{
The environment in which behaviours are learned: a pilot assessment of high school teaching kitchens as food safety learning environments in Ontario
}

\author{
Kristin M. Brown**, Kenneth J. Diplock* ${ }^{* \dagger}$ and Shannon E. Majowicz ${ }^{*}$ \\ *School of Public Health and Health Systems, University of Waterloo, Waterloo, Ontario, N2L 3G1, Canada. \\ †School of Health and Life Sciences and Community Services, Conestoga College Institute of Technology and Advanced Learning, Kitchener, \\ Ontario, N2G 4M4, Canada.
}

\begin{abstract}
Youth represent a unique audience for consumer food safety education and incorporating such education into existing curricula could facilitate delivery. However, successful delivery may depend, in part, on the facilities in which said training occurs. Since little is known about school teaching kitchen set-ups as related to food safety education, we conducted a pilot assessment of the physical learning environment of four Ontario high school teaching kitchen classrooms. We visited each classroom three times and assessed its characteristics using a modified version of the provincial food premises inspection report. Kitchen layout varied by school, and it was the built classroom characteristic with the greatest potential impact. Several characteristics unique to school teaching kitchens were noted, including whether the classroom teaching area and food preparation area were separated. Despite the variation between classrooms, all had physical characteristics sufficient to meet the minimum requirements for food service premises in Ontario. Nevertheless, this pilot assessment highlights nuanced factors unique to high school teaching kitchen classrooms that may impact the delivery of food safety education and the development of safe food handing behaviours. Findings can support conversations between public health, food safety authorities, and school stakeholders to enhance food safety learning environments in schools.
\end{abstract}

Key words: food safety, schools, adolescent, foodborne diseases, prevention and control

Youth represent a unique audience for food safety education. Both youth (middle and high school aged) and young adults (18-25 years) consume high-risk foods (Byrd-Bredbenner et al., 2007b; Morrone and Rathbun, 2003; Nesbitt et al., 2009; Unklesbay et al., 1998), lack food preparation experience and food safety skills (Abbot et al., 2012; Haapala and Probart, 2004; Morrone and Rathbun, 2003; Nesbitt et al., 2009), and appear to have low food safety knowledge (Abbot et al., 2009; Majowicz et al., 2015). As well, young adults are one of the groups most likely to mishandle food (Byrd-Bredbenner et al., 2013), appearing to engage in less than half the recommended food safety behaviours when observed preparing a meal (ByrdBredbenner et al., 2007a). Young adults are also less likely to read handling instructions for raw meat and poultry (Morrone and Rathbun, 2003) and to check refrigerator temperatures and know that processed meats should be refrigerated (Unklesbay et al., 1998).

Corresponding author: Shannon Majowicz (email: smajowicz@ uwaterloo.ca)

The authors contributed equally and are listed in alphabetical order.
Various food safety education and training programs aimed at youth and young adults have been evaluated, and they have been shown to improve self-reported knowledge, attitudes, and practices in middle school students (Lynch et al., 2008) and college undergraduates (Abbot et al., 2012; Stein et al., 2010; Yarrow et al., 2009), and observed behaviours in university students (Milton and Mullan, 2012), suggesting that food safety education for youth and young adults is effective. Practically, incorporating existing food safety training materials into current education structures could facilitate delivery. In Ontario, food safety is explicit in the high school curriculum, where several elective social science courses have food safety learning objectives (Ontario Ministry of Education, 2013). Ontario also has a standardized provincial food handler training program (Ontario Ministry of Health and Long-Term Care, 2013), delivered by local public health agencies across the province, that has traditionally been geared toward commercial food handlers. Consequently, delivering existing food handler training to youth via high school classes may be a reasonable way to provide this demographic with food safety education.

Aside from selecting an effective education program for use within schools, successful delivery may depend, in part, on the 
facilities in which training occurs. Because kitchen characteristics (e.g., inaccessible or inadequate hand-washing facilities (Allwood et al., 2004; Eves et al., 2006; Pragle et al., 2007) or absence of food thermometers (Sloan-Gardner et al., 2014)) can shape safe food handling behaviours, it is possible that kitchen set-up could impact the potential effectiveness of food safety education by influencing the food handling behaviours enacted in the classroom. Although food safety has been evaluated in school food service kitchens (e.g., cafeteria kitchens (da Cunha et al., 2014; Henroid and Sneed, 2004; Liz Martins and Rocha, 2014; Tóth and Bittsánszky, 2014)), little is known about high school teaching kitchen classrooms. Thus, our objective was to assess, in a pilot sample of high schools, factors associated with the physical set-up of teaching kitchen classrooms that might impact the learning environment for food safety education.

\section{Methods}

Four high school teaching kitchen classrooms, involved in an in-depth study about food safety education for students in Ontario (Majowicz et al., 2015), were assessed. These classrooms were located in four schools, in two school boards, and across three health units' jurisdictions; schools had an enrolment circa 750 students and were located within the Greater Golden Horseshoe and southwestern regions of Ontario. Each classroom was visited three times between February and June 2015, inclusive. During visit one we photographed classroom layout and conducted a full observation (described later); on subsequent visits we noted any changes to the observations from the previous visit(s). All 12 observations were made by a single certified public health inspector with 10 years' experience conducting food safety inspections of food premises (KD).

We developed the checklist of observable factors by modifying the Ontario provincial food premises inspection report (Ontario Ministry of Health and Long-term Care forms: "Items Critical to Food Safety" - 1141-64 (2005/09); "Establishment Sanitation, Design and Maintenance Items" 2735-64 (99/09)) to be applicable to teaching kitchen classrooms, as follows. Because we were only observing the physical set-up of the classroom, inspection items relating to behaviour of individuals within the classroom were either omitted (e.g., "washing hands thoroughly before and after handling food") or changed to reflect the portion of the inspection item related to the physical space (e.g., "food contact surfaces washed-rinsedsanitized after each use..." was changed to "food contact surfaces were clean"). Inspection items that were irrelevant given the school setting (e.g., "prohibited use of tobacco") were omitted. We added several new items, unique to school teaching kitchens, including whether: the classroom was also a routinely inspected food premises; there was separation between the food preparation facilities (e.g., counters, stoves) and the regular classroom (e.g., desks, chairs, whiteboard); and there was adequate space to store noncooking personal items such as backpacks. Each checklist item was recorded as "met," "did not meet," or "not observed," where "met" and "did not meet" were evaluated in the same way compliance would have been evaluated had the facility been a food premises undergoing a public health inspection. A detailed explanation was recorded for any items considered not met or not observed. The list of assessed factors is provided in Table 1; the checklist, formatted for use, is available as Supplementary Data ${ }^{1}$. We analysed data descriptively in Microsoft Excel 2011 version 14 (2010, Microsoft Corp.), to identify features of classrooms with the potential to impact both the delivery of food handler training and safe food handling behaviours.

\section{Results}

\section{Characteristics of the built classroom}

Kitchen layout varied by school (Table 2) and was the built classroom characteristic with the greatest potential impact on food safety education and food handling behaviours. One teaching kitchen was set up as a commercial kitchen, with single, large-capacity commercial-grade appliances, stainless steel counters, and a commercial three-compartment sink. The other three kitchens had home economics, domestic-style layouts, with multiple workstations designed for small groups of students, each consisting of a stove and oven unit, a sink, and counter and cupboard space. Three of the four kitchen classrooms had immoveable countertop/cabinet combinations as workstations, whereas in one classroom workstations were moveable tables that could be rearranged depending on the volume of students.

Although all classrooms had multiple sinks, one did not have a dedicated hand-washing sink. Further, in one of the three classrooms with a dedicated sink, the hand-washing sink was located such that students had to leave the food preparation area and walk through the desk area to wash their hands. Also, in one classroom, an overhead storage compartment above the handwashing sink presented the potential for head injuries. Three of the four classrooms had adequate space for air-drying dishes, but in one there was only a single, small area (about the size of a domestic drying rack) provided for air-drying dishes. Three of the four classrooms had adequate protection against the entrance of vermin, but one had a large, floor-to-ceiling door that opened to the outdoors, within the food preparation area, which could be opened by the students during food preparation.

Aside from kitchen layout, the other built characteristics of all four classrooms were generally conducive to food safety education and proper food handling. All food and nonfood contact surfaces were clean and were in good repair, with the exception of Visit 3 to one classroom, when the refrigerator door handle had been temporarily fixed with duct tape. All classrooms had adequate freezer capacity, in the form of commercial or domestic freezers, all held at or below $-18^{\circ} \mathrm{C}\left(0^{\circ} \mathrm{F}\right)$, with the exception of Visit 1 in one classroom, when the freezer was at $-10^{\circ} \mathrm{C}$.

\section{Characteristics related to supplies and consumables}

The characteristics with the greatest potential impact on food safety education and proper food handling pertained to hygiene supplies and thermometers, although it was infrequent that

\footnotetext{
${ }^{1}$ Supplementary data are available with the article through the journal Web site at http://pubs.ciphi.ca/doi/suppl/10.5864/d2016-018.
} 
Table 1. School compliance with checklist items used to assess the physical learning environment of high school teaching kitchen classrooms relating to food safety education and food handler training

\begin{tabular}{|c|c|c|c|}
\hline \multirow[b]{2}{*}{ Criteria } & \multicolumn{3}{|c|}{$\begin{array}{l}\text { Number of schools } \\
\text { compliant* }^{*}\end{array}$} \\
\hline & Visit 1 & Visit 2 & Visit 3 \\
\hline \multicolumn{4}{|l|}{ Equipment and utensils } \\
\hline Utensils available for use by students when eating food prepared & $4 / 4$ & $4 / 4$ & $4 / 4$ \\
\hline Proper storage of clean utensils & $4 / 4$ & $4 / 4$ & $4 / 4$ \\
\hline $\begin{array}{l}\text { Nonfood contact surfaces and equipment properly designed, constructed, installed, and } \\
\text { maintained }\end{array}$ & $4 / 4$ & $4 / 4$ & $3 / 4$ \\
\hline $\begin{array}{l}\text { Food contact surfaces properly designed, constructed, installed, located (smooth, nonabsorbent, } \\
\text { cleanable, corrosion resistant, and nontoxic) }\end{array}$ & $4 / 4$ & $4 / 4$ & $4 / 4$ \\
\hline Nonfood contact surfaces and equipment are accessible for cleaning & $4 / 4$ & $4 / 4$ & $4 / 4$ \\
\hline Commercial grade equipment (refrigerators, freezers, stoves) & $2 / 4$ & $2 / 4$ & $2 / 4$ \\
\hline \multicolumn{4}{|l|}{ Food handler hygiene and activities } \\
\hline Clean outer garments are available for students' use (clean uniforms or clean aprons) & $4 / 4$ & $4 / 4$ & $4 / 4$ \\
\hline Students had the supplies needed to ensure hair was suitably confined (e.g., chef hat, ball cap, hair nets) & $4 / 4$ & $4 / 4$ & $4 / 4$ \\
\hline \multicolumn{4}{|l|}{ Equipment and utensils sanitation } \\
\hline Mechanical dishwashing & $2 / 2$ & $2 / 2$ & $2 / 2$ \\
\hline Manual dishwashing: wash-rinse-sanitize technique & $3 / 3$ & $2 / 4$ & $4 / 4$ \\
\hline Three-compartment sink method & $2 / 2$ & $1 / 2$ & $2 / 2$ \\
\hline Two-compartment sink method & $1 / 1$ & $1 / 1$ & $1 / 1$ \\
\hline One sink and bucket method & $1 / 1$ & $0 / 1$ & $1 / 1$ \\
\hline Adequate space and equipment provided for air drying & $3 / 4$ & $3 / 4$ & $3 / 4$ \\
\hline Sanitize test kit/thermometer readily available & $0 / 3$ & $0 / 3$ & $0 / 3$ \\
\hline Food contact and noncontact surfaces were clean, organized, and in good repair & $4 / 4$ & $4 / 4$ & $4 / 4$ \\
\hline $\begin{array}{l}\text { Wiping cloths and sanitizing solution available, and sanitizing solution clearly identified (e.g., } \\
\text { labelled bottle or color-coded bucket) }\end{array}$ & $3 / 4$ & $3 / 4$ & $4 / 4$ \\
\hline Chlorine or quat or other & $4 / 4$ & $4 / 4$ & $4 / 4$ \\
\hline Bucket or spray bottle or other & $2 / 4$ & $2 / 4$ & $4 / 4$ \\
\hline \multicolumn{4}{|l|}{ Sanitary facilities and controls } \\
\hline Approved municipal/private sewage disposal where required & $4 / 4$ & $4 / 4$ & $4 / 4$ \\
\hline $\begin{array}{l}\text { Separate hand-washing sink in each preparation area with required supplies: liquid soap in a } \\
\text { dispenser and paper towel }\end{array}$ & $4 / 4$ & $3 / 4$ & $4 / 4$ \\
\hline Sanitary maintenance of and provision of required supplies in nearby school washrooms & $4 / 4$ & $4 / 4$ & $4 / 4$ \\
\hline \multicolumn{4}{|l|}{ Garbage and waste management } \\
\hline Insect- and vermin-proof containers provided where required & $4 / 4$ & $4 / 4$ & $4 / 4$ \\
\hline Frequency of garbage removal adequate to maintain the premises in a sanitary condition & $4 / 4$ & $4 / 4$ & $4 / 4$ \\
\hline
\end{tabular}


Table 1 (continued).

\begin{tabular}{|c|c|c|c|}
\hline \multirow{2}{*}{ Criteria } & \multicolumn{3}{|c|}{$\begin{array}{l}\text { Number of schools } \\
\text { compliant* }\end{array}$} \\
\hline & Visit 1 & Visit 2 & Visit 3 \\
\hline \multicolumn{4}{|l|}{ Pest control } \\
\hline Adequate protection against the entrance of insects, vermin, rodents, dust, and fumes & $4 / 4$ & $4 / 4$ & $3 / 4$ \\
\hline \multicolumn{4}{|l|}{ Sanitary maintenance and construction } \\
\hline Floor, walls, and ceiling clean/in good repair & $4 / 4$ & $4 / 4$ & $4 / 4$ \\
\hline Mechanical ventilation operable where required & $4 / 4$ & $4 / 4$ & $4 / 4$ \\
\hline Lighting adequate for food preparation and cleaning & $4 / 4$ & $4 / 4$ & $4 / 4$ \\
\hline General housekeeping satisfactory & $4 / 4$ & $4 / 4$ & $4 / 4$ \\
\hline \multicolumn{4}{|l|}{ Refrigerated and frozen food storage of hazardous food } \\
\hline Cold holding: $4{ }^{\circ} \mathrm{C}\left(40{ }^{\circ} \mathrm{F}\right)$ & $4 / 4$ & $4 / 4$ & $4 / 4$ \\
\hline Freezing: $-18^{\circ} \mathrm{C}\left(0^{\circ} \mathrm{F}\right)$ & $2 / 3$ & $3 / 3$ & $3 / 3$ \\
\hline \multicolumn{4}{|l|}{ Cooking/hot holding/reheating of hazardous foods } \\
\hline Thermometers present to verify food preparation and storage temperatures: & $2 / 3$ & $2 / 3$ & $2 / 3$ \\
\hline Indicator thermometers present and adequately located in fridges/freezers & $3 / 4$ & $3 / 4$ & $3 / 4$ \\
\hline Probe thermometers available for use & $4 / 4$ & $4 / 4$ & $4 / 4$ \\
\hline \multicolumn{4}{|l|}{ Protection from contamination by food handlers } \\
\hline Access to utensils to minimize direct hand contact during food preparation & $4 / 4$ & $4 / 4$ & $4 / 4$ \\
\hline \multicolumn{4}{|l|}{ Protection from adulteration and contamination } \\
\hline Raw foods separated from ready-to-eat foods during storage & $4 / 4$ & $4 / 4$ & $4 / 4$ \\
\hline Constant supply of hot and cold potable running water where applicable & $4 / 4$ & $4 / 4$ & $4 / 4$ \\
\hline Food protected from potential contamination (e.g. covered, labelled, off floor) & $4 / 4$ & $4 / 4$ & $4 / 4$ \\
\hline Chemicals stored separately from food & $4 / 4$ & $4 / 4$ & $4 / 4$ \\
\hline High acid food stored/prepared in corrosion resistant contains or equipment & $4 / 4$ & $4 / 4$ & $4 / 4$ \\
\hline \multicolumn{4}{|l|}{ Other school-specific items } \\
\hline Separation of food preparation area from classroom/desk teaching area & $2 / 4$ & $2 / 4$ & $2 / 4$ \\
\hline Adequate storage/space for noncooking material (back packs, coats, school supplies) & $4 / 4$ & $4 / 4$ & $4 / 4$ \\
\hline Kitchen routinely inspected by local Public Health Unit & $2 / 4$ & $2 / 4$ & $2 / 4$ \\
\hline Safe storage of knives & $4 / 4$ & $4 / 4$ & $4 / 4$ \\
\hline Nonslip surfaces used for cutting boards & $2 / 4$ & $2 / 4$ & $2 / 4$ \\
\hline $\begin{array}{l}\text { Classroom design/layout provides adequate space for students to prepare food and cleanand } \\
\text { sanitize safely }\end{array}$ & $4 / 4$ & $4 / 4$ & $4 / 4$ \\
\hline Cell phones prohibited from food preparation areas & $2 / 4$ & $2 / 4$ & $2 / 4$ \\
\hline
\end{tabular}

*Note: Schools that received a "not applicable" for an item are not included in the denominator for that item. 
Table 2. Description of the general physical set-up of high school teaching kitchen classrooms included in this pilot study

\begin{tabular}{|c|c|c|c|c|}
\hline \multirow[b]{2}{*}{$\begin{array}{l}\text { Classroom } \\
\text { attribute }\end{array}$} & \multicolumn{4}{|c|}{ Details } \\
\hline & Classroom 1 & Classroom 2 & Classroom 3 & Classroom 4 \\
\hline $\begin{array}{l}\text { Type of physical } \\
\text { layout of } \\
\text { classroom } \\
\text { kitchen }\end{array}$ & $\begin{array}{l}\text { Combined: domestic-type } \\
\text { stoves, individual sinks } \\
\text { and counters with } \\
\text { commercial dishwashing } \\
\text { area }\end{array}$ & Commercial & Domestic & Domestic \\
\hline $\begin{array}{l}\text { Separation of } \\
\text { food preparation } \\
\text { and desk areas }\end{array}$ & $\begin{array}{l}\text { Separated by a physical } \\
\text { partial wall }\end{array}$ & $\begin{array}{l}\text { Separated by self- } \\
\text { closing door; teaching } \\
\text { kitchen shared space } \\
\text { with a separate } \\
\text { commercial kitchen }\end{array}$ & No clear separation & No clear separation \\
\hline \multirow[t]{3}{*}{ Appliances } & $\begin{array}{l}\text { Commercial-grade six- } \\
\text { door refrigerator and } \\
\text { three-door upright freezer }\end{array}$ & $\begin{array}{l}\text { Commercial-grade two- } \\
\text { door refrigerator and } \\
\text { two-door upright freezer }\end{array}$ & $\begin{array}{l}\text { Commercial-grade two- } \\
\text { door refrigerator and } \\
\text { domestic-grade freezer }\end{array}$ & $\begin{array}{l}\text { Domestic-grade } \\
\text { refrigerators with } \\
\text { freezers }\end{array}$ \\
\hline & Domestic-grade ovens & $\begin{array}{l}\text { Commercial-grade } \\
\text { ovens }\end{array}$ & Domestic-grade ovens & $\begin{array}{l}\text { Domestic-grade } \\
\text { ovens }\end{array}$ \\
\hline & Mechanical dishwasher & $\begin{array}{l}\text { No mechanical } \\
\text { dishwasher }\end{array}$ & Mechanical dishwasher & $\begin{array}{l}\text { No mechanical } \\
\text { dishwasher }\end{array}$ \\
\hline $\begin{array}{l}\text { Food contact } \\
\text { surfaces }\end{array}$ & Stainless steel & Stainless steel & Laminate countertops & $\begin{array}{l}\text { Laminate } \\
\text { countertops }\end{array}$ \\
\hline $\begin{array}{l}\text { Sinks in the } \\
\text { classroom }\end{array}$ & $\begin{array}{l}\text { One shared three- } \\
\text { compartment sink; single } \\
\text { sinks at workstations; } \\
\text { one separate, dedicated } \\
\text { hand-washing sink }\end{array}$ & $\begin{array}{l}\text { One shared three- } \\
\text { compartment sink; one } \\
\text { separate, dedicated } \\
\text { hand-washing sink }\end{array}$ & $\begin{array}{l}\text { Single sinks at } \\
\text { workstations; one } \\
\text { separate, dedicated hand- } \\
\text { washing sink located } \\
\text { outside the food } \\
\text { preparation area }\end{array}$ & $\begin{array}{l}\text { Two-compartment } \\
\text { sinks at } \\
\text { workstations; no } \\
\text { dedicated hand- } \\
\text { washing sink }\end{array}$ \\
\hline $\begin{array}{l}\text { Dishwashing } \\
\text { set-up }\end{array}$ & $\begin{array}{l}\text { Shared three-compartment } \\
\text { sink and single sinks at } \\
\text { workstations;air or towel } \\
\text { dry }\end{array}$ & $\begin{array}{l}\text { Shared three- } \\
\text { compartment sink; air } \\
\text { or towel dry }\end{array}$ & $\begin{array}{l}\text { Single sink and counter- } \\
\text { top bucket at } \\
\text { workstations; air or towel } \\
\text { dry }\end{array}$ & $\begin{array}{l}\text { Two-compartment } \\
\text { sinks at } \\
\text { workstations; air or } \\
\text { towel dry }\end{array}$ \\
\hline $\begin{array}{l}\text { Food handler } \\
\text { hygiene }\end{array}$ & Aprons and hats available & $\begin{array}{l}\text { Aprons and hair nets } \\
\text { available }\end{array}$ & $\begin{array}{l}\text { Aprons and chef hats } \\
\text { available }\end{array}$ & $\begin{array}{l}\text { Aprons and hair nets } \\
\text { available }\end{array}$ \\
\hline
\end{tabular}

classrooms did not meet checklist criteria. Only one classroom had test strips available to verify adequate sanitizer concentrations. During the first two of three visits, one classroom provided spray bottles of what appeared to be a sanitizing solution, although the bottles were unlabelled. Also during the first two of three visits, another did not have sanitizer stocked and available in the classroom.

All classrooms had soap and paper towels available for hand washing within the kitchen, although in one there was no paper towel dispenser and the paper towels were stacked loosely beside the sink (presenting an opportunity for contamination); in another, during Visit 2, the in-class paper towel dispensers were empty. The school bathrooms nearest to all classrooms were adequately stocked with liquid hand soap during all visits.
In all four schools there were hand dryers in the washrooms instead of paper towels, and in three of the four schools the force of air from these hand dryers was insufficient to dry hands completely. All classrooms had probe thermometers available at student workstations during all three visits, although these thermometers had been supplied as part of the in-depth study. Three of the four classrooms had thermometers present and adequately located in the refrigerators and freezers.

All other characteristics related to supplies and consumables appeared conducive to food safety education and proper food handling. For example, all classrooms had adequate and properly stored equipment and utensils available for use, including locked knife storage. 


\section{Characteristics unique to school-based teaching kitchens}

In addition to the standard characteristics typically assessed for food premises, we noted additional characteristics unique to high school teaching kitchen classrooms. In two classrooms, the area containing the desks, chairs, and personal belongings (e.g., backpacks, electronic devices) was not clearly separated from the food preparation area, and in one of these classrooms some cooking equipment was stored in the desk area due to space constraints. These two classrooms were both single, unpartitioned rooms, that allowed desks and tables at the back of the desk area to be used as food preparation surfaces, and allowed students to take personal belongings back and forth easily between desk and kitchen spaces. None of the four classrooms had posted instructions prohibiting, or physical barriers preventing, students from taking backpacks, cell phones, or other personal belongings in to the kitchen space (although there was adequate space to store personal belongings in the desk area of all four classrooms).

In all four classrooms, teachers restricted access to supplies they deemed potentially dangerous; knives were stored securely in locked storage and student access to sanitizing chemicals was restricted, in ways that ranged from students requiring teacher permission to retrieve and use the chemical to the teacher being the only person to handle sanitizer. Two reasons for this were given: teachers considered students to be vulnerable minors who should not handle chemicals unless necessary, and teachers were hesitant to allow students to use bleach that might damage clothing or belongings because of potential parental upset. In addition to knife and chemical safety, two classrooms had nonslip pads available to be put under cutting boards to minimize the risk of knife slips and injuries.

\section{School kitchen compliance with expectations for commercial food premises}

Two classrooms were also routinely inspected food premises, and evidence of an "unconditional pass" (i.e., substantial compliance with the Ontario Food Premises Regulations R.R.O. 1990, Reg. 562) from the latest inspection was posted. As expected, the classroom with the fewest items categorized as "not met" (1 item on 1 visit) was an inspected kitchen, whereas the classroom with the most items categorized as "not met" (6 distinct items, recorded 13 times, over 3 visits) was not inspected and had a domestic layout. The "not met" items in this classroom were typical of domestic kitchens, and included: not having test strips available to verify adequate sanitizer concentrations, not having thermometers inside the domestic refrigerators and freezers, and not having nonslip surfaces under cutting boards. Interestingly, in all four classrooms, the "not met" items observed would have been considered minor compliance issues had these been official inspections, such that all school kitchens would have been permitted to continue operating.

\section{Discussion}

We conducted a pilot assessment of the physical learning environment of four high school teaching kitchen classrooms in Ontario, vis-a-vis food safety education, by applying a modified version of the provincial food premises inspection report. Although classrooms varied in layout and other attributes, and only two were routinely inspected food premises, all had physical characteristics sufficient to meet the minimum requirements for food service premises in Ontario (Government of Ontario, 1990); this was positive, since all four teaching kitchen classrooms in this pilot (whether inspected or not) were used to prepare food for school events. Notwithstanding, our assessment highlighted several considerations for food safety education and food handler training in high schools that may warrant further attention.

Here, teaching kitchen set-ups varied from fully domestic to fully commercial layouts. Understandably, kitchen classrooms with domestic set-ups had more items "not met"; however, these were all easily remedied minor issues. Thus, schools with domestic teaching kitchen set-ups may wish to consider the following small-scale adaptations to enhance their students' ability to develop relevant commercial food handling skills: (i) provide test-strips for sanitizers used in the kitchens; (ii) label spray bottles and mark them with sanitizer and water measurements to ensure adequate concentrations at each refill; (iii) maintain cooking and cold holding temperature logs to ensure safe food preparation and storage temperatures; (iv) in classrooms where students are allowed to bring their own aprons or hats from home, ensure aprons and hats are clean for each class; and $(v)$ require students to wear closed-toed, nonslip shoes. In addition to considering these recommendations, inviting public health and food safety authorities to assess individual teaching kitchen set-ups could help identify additional classroom-specific areas for enhancement.

Another area where the teaching kitchen classroom set-up may impact the development of food safety behaviours was related to hand washing; one classroom did not have a dedicated hand-washing sink and in another the hand-washing sink was located inconveniently outside the kitchen area. The potential impact of this on the development of proper hand hygiene habits is unclear. Although lack of a dedicated handwashing sink precludes developing the habit of using one, the impact on developing and practicing proper hand hygiene overall, including in future domestic situations where dedicated hand-wash facilities rarely exist, is unknown. Clearly, unavailable, inaccessible, and poorly stocked hand-washing facilities contribute to poor hand hygiene (Allwood et al., 2004; Pragle et al., 2007; Sloan-Gardner et al., 2014; Todd et al., 2010). However, given the presence of adequate (albeit not dedicated) hand-washing facilities, the extent to which teaching kitchen classroom set-ups need to mimic future food handling environments (e.g., restaurant kitchens, home kitchens) to support proper hand hygiene habits in those environments bears further investigation.

Several other small-scale adaptations that could enhance the development of proper food safety habits were identified, and 
specific recommendations resulting from this pilot were for schools to: (i) add shelving, where possible, above and around sink areas to allow more space for air-drying; (ii) provide nonslip pads to place under cutting boards, to minimize the risk for knife slips and injuries; (iii) encourage students not to enter the desk area when preparing food or alternately to wash their hands when returning from doing so; and (iv) encourage students to leave cell phones, backpacks, and other personal items at their desks or in their lockers (i.e., outside of the food preparation area) and not to handle these items while preparing food. The latter two recommendations in particular align with important food safety issues found also in domestic settings, where consumers use home kitchens for more than just food preparation and often have items such as purses, pets, and laundry present in food preparation areas (Byrd-Bredbenner et al., 2013). That students may face similar food safety issues in high school teaching kitchen classrooms as they do (or will) in home kitchens offers a unique opportunity to develop appropriate safe food handling behaviours to address these risks.

In this pilot, one of the four kitchen classrooms was a renovated space that had previously served as a workshop. Although guidance exists on the construction and reconstruction of food service establishments (e.g., Manitoba Health, Healthy Living, and Seniors, 2016) and the remodelling of community and church kitchens (Iowa State University, 2009) with respect to ensuring food safety, similar information is not readily available to schools or school boards when they construct or renovate teaching kitchen classrooms. Involving public health and food safety authorities when planning new or renovated teaching kitchen classrooms could help minimize food safety risks given constraints such as built structures and spaces and resource limitations.

This pilot assessment is subject to several limitations, most importantly the inclusion of only four classrooms. Whether these findings are relevant for other classrooms, schools, or jurisdictions is unknown. As well, it is possible that the schools' participation in the larger in-depth study about food safety education may have impacted aspects of food safety assessed here, in particular easily changed factors such as garbage removal. However, given that the majority of factors we assessed were structural, or difficult to easily modify by either the classroom teachers or the schools (e.g., because of board procurement procedures), it is unlikely that schools appreciably altered the factors we assessed here because of their participation in the larger study. Another limitation is that we did not assess the adequacy of the physical space in relation to a given volume of students. How the number of students in a given space might alter or introduce additional food safety risks (e.g., peer behaviour enforcement, increased potential for crosscontamination) is unclear, and future studies should consider how the kitchen classroom environment intersects with the individuals in these spaces. Given that the high school built environment influences student health behaviours such as physical activity (Hobin et al., 2012; Leatherdale et al., 2010), nutrition (Terry-McElrath et al., 2014), and obesity (Driessen et al., 2014; Mâsse et al., 2014; Terry-McElrath et al.,
2015), it is reasonable to hypothesize it also influences safe food handling practices. Future research should assess the impact of the high school environment on actual food safety behaviours among students and staff, within kitchen classrooms and in general.

Despite the above limitations, this pilot offers a tool for assessing the adequacy of high school teaching kitchen classrooms for food safety education, and highlights nuanced factors unique to such classrooms that may impact the delivery of food safety education and the development of safe food handing behaviours. These findings can inform future, more extensive assessments of school teaching kitchen environments and can prompt conversations between public health and food safety authorities, and teachers, schools, and school boards on topics ranging from small-scale, classroom-specific adaptations to support food safety learning environments to guidelines for planning new or renovated teaching kitchen spaces.

\section{Acknowledgements}

The authors thank the participating schools (including the principals, teachers, and school boards) for their support of this study. This research was funded by the Ontario Ministry of Agriculture, Food and Rural Affairs' Food Safety Research Program (FS2013-1843; grant awarded to SE Majowicz). This research built off an existing research platform (COMPASS) supported by an operating grant from the Canadian Institutes of Health Research (CIHR) Institute of Population and Public Health (IPPH) (MOP-114875; grant awarded to ST Leatherdale).

\section{References}

Abbot, J.M., Byrd-Bredbenner, C., Schaffner, D., Bruhn, C.M., and Blalock, L. 2009. Comparison of food safety cognitions and selfreported food-handling behaviors with observed food safety behaviors of young adults. Eur. J. Clin. Nutr, 63(4): 572-579. doi: $10.1038 /$ sj.ejcn.1602961.

Abbot, J.M., Policastro, P., Bruhn, C., Schaffner, D.W., and ByrdBredbenner, C. 2012. Development and evaluation of a university campus-based food safety media campaign for young adults. J. Food Prot, 75(6): 1117-1124. doi: 10.4315/0362-028X.JFP-11-506.

Allwood, P.B., Jenkins, T., Paulus, C., Johnson, L., and Hedberg, C.W. 2004. Hand washing compliance among retail food establishment workers in Minnesota. J. Food Prot, 67(12): 2825-2828.

Byrd-Bredbenner, C., Berning, J., Martin-Biggers, J., and Quick, V. 2013. Food safety in home kitchens: A synthesis of the literature. Int. J. Environ. Res. Public Health, 10(9): 4060-4085. doi: 10. 3390/ijerph10094060.

Byrd-Bredbenner, C., Maurer, J., Wheatley, V., Cottone, E., and Clancy, M. 2007a. Observed food safety behaviours of young adults. Br. Food J, 109(7): 519-530. doi: 10.1108/00070700710761518.

Byrd-Bredbenner, C., Maurer, J., Wheatley, V., Schaffner, D., Bruhn, C., and Blalock, L. 2007b. Food safety self-reported behaviors and cognitions of young adults: Results of a national study. J. Food Prot, 70(8): 1917-1926. 
da Cunha, D.T., Stedefeldt, E., and de Rosso, V.V. 2014. The use of health risk scores and classification in food service: An experience in Baixada Santista's public schools - Brazil. Br. Food J, 116(5): 753-764. doi: 10.1108/BFJ-08-2012-0209.

Driessen, C.E., Cameron, A.J., Thornton, L.E., Lai, S.K., and Barnett, L.M. 2014. Effect of changes to the school food environment on eating behaviours and/or body weight in children: A systematic review. Obes. Rev, 15(12): 968-982. doi: 10.1111/obr.12224.

Eves, A., Bielby, G., Egan, B., Lumbers, M., Raats, M., and Adams, M. 2006. Food hygiene knowledge and self-reported behaviours of UK school children (4-14 years). Br. Food J, 108(9): 706-720. doi: 10.1108/00070700610688359.

Government of Ontario. 1990. Ontario Food Premises Regulations R.R.O. 1990, Reg. 562. Available at: https://www.ontario.ca/laws/ regulation/900562 [accessed 30 March 2016].

Haapala, I., and Probart, C. 2004. Food safety knowledge, perceptions, and behaviors among middle school students. J. Nutr. Educ. Behav, 36(2): 71-76. doi: 10.1016/S1499-4046(06)60136-X.

Henroid, D., Jr., and Sneed, J. 2004. Readiness to implement hazard analysis and critical control point (HACCP) systems in Iowa schools. J. Am. Diet. Assoc, 104(2): 180-185. doi: 10.1016/ j.jada.2003.11.009.

Hobin, E., Leatherdale, S., Manske, S., Dubin, J., Elliott, S., and Veugelers, P. 2012. A multilevel examination of factors of the school environment and time spent in moderate to vigorous physical activity among a sample of secondary school students in grades 9-12 in Ontario, Canada. Int. J. Public Health, 57(4): 699709. doi: $10.1007 / \mathrm{s} 00038-012-0336-2$.

Iowa State University. 2009. Remodeling community or church kitchens. Available at: http://store.extension.iastate.edu/Product/ Remodeling-Community-or-Church-Kitchens-PDF [accessed 30 March 2016].

Leatherdale, S.T., Manske, S., Faulkner, G., Arbour, K., and Bredin, C. 2010. A multi-level examination of school programs, policies and resources associated with physical activity among elementary school youth in the PLAY-ON study. Int. J. Behav. Nutr. Phys. Act, 7: 6. doi: 10.1186/1479-5868-7-6.

Liz Martins, M., and Rocha, A. 2014. Evaluation of prerequisite programs implementation at schools foodservice Food Control, 39(1): 30-33. doi: 10.1016/j.foodcont.2013.10.040.

Lynch, R.A., Steen, M.D., Pritchard, T.J., Buzzell, P.R., and Pintauro, S.J. 2008. Delivering food safety education to middle school students using a web-based, interactive, multimedia, computer program. J. Food Sci. Educ, 7(2): 35-42. doi: 10.1111/j.15414329.2007.00046.x.

Majowicz, S.E., Diplock, K.J., Leatherdale, S.T., Bredin, C.T., Rebellato, S., Hammond, D., et al. 2015. Food safety knowledge, attitudes and self-reported practices among Ontario high school students. Can. J. Public Health, 106(8): e520-e526.

Manitoba Health, Healthy Living, and Seniors. 2016. Guideline for the design, construction and reconstruction of a food handling establishment (Guideline \#HPU12-05). Available at: https://www. gov.mb.ca/health/publichealth/environmentalhealth/protection/docs/ construction.pdf [accessed 30 March 2016].

Mâsse, L.C., de Niet-Fitzgerald, J.E., Watts, A.W., Naylor, P.-J., and Saewyc, E.M. 2014. Associations between the school food environment, student consumption and body mass index of Canadian adolescents. Int. J. Behav. Nutr. Phys. Act, 11(1): 29. doi: 10.1186/ 1479-5868-11-29.

Milton, A.C., and Mullan, B.A. 2012. An application of the theory of planned behavior - A randomized controlled food safety pilot intervention for young adults Health Psychol, 31(2): 250-259. doi: $10.1037 / \mathrm{a} 0025852$.

Morrone, M., and Rathbun, A. 2003. Health education and food safety behavior in the university setting. J. Environ. Health, 65(7): 9-15.

Nesbitt, A., Majowicz, S., Finley, R., Marshall, B., Pollari, F., Sargeant, J., et al. 2009. High-risk food consumption and food safety practices in a Canadian community. J. Food Prot, 72(12): 25752586.

Ontario Ministry of Education. 2013. The Ontario curriculum, grades 9 to 12: Social sciences and humanities (revised). Available at: https://www.edu.gov.on.ca/eng/curriculum/secondary/ssciences9to122013.pdf [accessed 30 March 2016].

Ontario Ministry of Health and Long-Term Care. 2013. Food safety: A guide for Ontario's food handlers. Available at: http://www. health.gov.on.ca/en/pro/programs/publichealth/enviro/docs/training_manual.pdf [accessed 30 March 2016].

Pragle, A.S., Harding, A.K., and Mack, J. C. 2007. Food workers' perspectives on handwashing behaviors and barriers in the restaurant environment. J. Environ. Health, 69: 27-32.

Sloan-Gardner, T.S., Glynn-Robinson, A.-J., Roberts-Witteveen, A., Krsteski, R., Rogers, K., Kaye, A., et al. 2014. An outbreak of gastroenteritis linked to a buffet lunch served at a Canberra restaurant. Commun. Dis. Intell. Q. Rep, 38(4): E273-E278.

Stein, S.E., Dirks, B.P., and Quinlan, J.J. 2010. Assessing and addressing safe food handling knowledge, attitudes, and behaviors of college undergraduates. J. Food Sci. Educ, 9(2): 47-52. doi: 10.1111/j.1541-4329.2010.00092.x.

Terry-McElrath, Y.M., O'Malley, P.M., and Johnston, L.D. 2014. Accessibility over availability: Associations between the school food environment and student fruit and green vegetable consumption. Child. Obes, 10(3): 241-250. doi: 10.1089/chi.2014.0011.

Terry-McElrath, Y.M., O’Malley, P.M., and Johnston, L.D. 2015. Potential impact of national school nutritional environment policies: Cross-sectional associations with US secondary student overweight/obesity, 2008-2012 JAMA Pediatr, 169(1): 78-85. doi: $10.1001 /$ jamapediatrics.2014.2048.

Todd, E.C.D., Greig, J.D., Michaels, B.S., Bartleson, C.A., Smith, D., and Holah, J. 2010. Outbreaks where food workers have been implicated in the spread of foodborne disease. Part 11. Use of antiseptics and sanitizers in community settings and issues of hand hygiene compliance in health care and food industries. J. Food Prot, 73(12): 2306-2320.

Tóth, A.J., and Bittsánszky, A. 2014. A comparison of hygiene standards of serving and cooking kitchens in schools in Hungary Food Control, 46: 520-524. doi: 10.1016/j.foodcont.2014.06.019.

Unklesbay, N., Sneed, J., and Toma, R. 1998. College students' attitudes, practices, and knowledge of food safety. J. Food Prot, 61(9): 1175-1180.

Yarrow, L., Remig, V.M., and Higgins, M.M. 2009. Food safety educational intervention positively influences college students' food safety attitudes, beliefs, knowledge, and self-reported practices. J. Environ. Health, 71(6): 30-35. 